\title{
La representación cinematográfica de la mucama latinoamericana: La ciénaga (Lucrecia Martel, 2001) y Roma (Alfonso Cuarón, 2018)*
}

\author{
Lucía-Gloria Vázquez-Rodríguez | luciaglv@ucm.es \\ Universidad Complutense de Madrid
}

Francisco A. Zurian | azurian@ucm.es

Universidad Complutense de Madrid

Palabras clave

"cine latinoamericano"; "cine háptico"; "neocolonialismo"; "Lucrecia Martel”; "Alfonso Cuarón"; "cine lento"

Sumario

1. Introducción

2. Metodología y marco teórico

3. Análisis y discusión de los resultados

3.1. La construcción del punto de vista: la perspectiva del niño y las imágenes hápticas

3.2. Un análisis desde el cine lento y la imagen-tiempo

4. Conclusiones

5. Bibliografía

\section{Resumen}

Dentro del cine latinoamericano cada vez encontramos más filmes que representan la naturaleza invisibilizada, neocolonialista y sexista de uno de los fenómenos más extendidos en el continente: la existencia de servicio doméstico entre las familias blancas de clase alta. Con un enfoque cualitativo que integra como categorías de análisis las características del lenguaje fílmico háptico definido por Laura Marks (2000) y la imagen-tiempo propia del cine lento (Deleuze, 1987) se argumenta la emergencia de un nuevo género cinematográfico en Latinoamérica que sitúa a la figura de la mucama en el centro formal, emocional y narrativo de los filmes, y que cada vez atrae más interés desde los estudios fílmicos. En este sentido, se analizarán dos visiones complementarias pero opuestas de la relación entre el servicio doméstico y las familias latinoamericanas de clase alta: La ciénaga (Martel, 2001), que sitúa a la mucama Isabel (Andrea López) en los márgenes visuales del texto fílmico, ofreciendo una visión crítica de la naturaleza explotadora del servicio doméstico; y Roma (Cuarón, 2018), cuyo enfoque nostálgico sitúa a Cleo (Yalitza Aparicio) en el centro afectivo de la narración sin pretender en ningún momento hablar en lugar de su subjetividad subalterna.

\section{Cómo citar este texto:}

Lucía-Gloria Vázquez-Rodríguez y Francisco A. Zurian (2021): La representación cinematográfica de la mucama latinoamericana: La ciénaga (Lucrecia Martel, 2001) y Roma (Alfonso Cuarón, 2018), en Miguel Hernández Communication Journal, Vol. 13 (1), pp. 101 a 122. Universidad Miguel Hernández, UMH (Elche-Alicante). DOI: 10.21134/mhjournal. v13i.1469

${ }^{*}$ Contratos predoctorales de personal investigador en formación financiados por la Universidad Complutense de Madrid y el Banco Santander 


\title{
Cinematic representations of Latin American domestic workers: La ciénaga (Lucrecia Martel, 2001) and Roma (Alfonso Cuarón, 2018)*
}

\author{
Lucía-Gloria Vázquez-Rodríguez | luciaglv@ucm.es
}

Universidad Complutense de Madrid

Francisco A. Zurian | azurian@ucm.es

Keywords

"Latin American Cinema"; "Haptic Cinema";

"neo-colonialism"; "Lucrecia Martel"; "Alfonso

Cuaron"; "slow cinema"

\section{Summary}

\section{Introduction}

2. Methodology and theoretical background

3. Analysis and discussion of the results

3.1. The construction of the point of view: the

child's perspective and haptic images

3.2. An analysis from slow cinema and the

image-time

4. Conclusions

5. Cited works

\section{Abstract}

Recent Latin American cinema is increasingly interested in the representation of the invisibilized, neocolonialist and sexist nature of the existence of domestic servantss amongst upper-class white families, one of the most widespread phenomena in the continent. Implementing a qualitative approach that integrates as categories for the analysis the traits of haptic filmic language (Marks, 2000) and the time-image typical of slow cinema (Deleuze, 1987), we argue the emergence of a new film genre in Latin America that places the figure of the maid in the formal, emotional and narrative center of the films,

and that increasingly attracts more interest from film studies. In this regard, we analyze two complementing yet opposing visions of the relationship between domestic service and upper-class Latin American families: La ciénaga (Martel, 2001), which places the maid Isabel (Andrea López) on the visual margins of the filmic text, offering a critical view of the exploitative nature of domestic service; and Roma (Cuarón, 2018), whose nostalgic approach locates Cleo (Yalitza Aparicio) at the center of the narrative while carefully avoiding any pretense to speak in place of her subaltern subjectivity.

Lucía-Gloria Vázquez-Rodríguez y Francisco A. Zurian (2021): La representación cinematográfica de la mucama latinoamericana: La ciénaga (Lucrecia Martel, 2001) y Roma (Alfonso Cuarón, 2018), en Miguel Hernández Communication Journal, Vol. 13 (1), pp. 101 a 122. Universidad Miguel Hernández, UMH (Elche-Alicante). DOI: 10.21134/mhjournal. v13i.1469 


\section{Introducción}

A lo largo de las últimas décadas, hemos sido testigos del éxito de algunos títulos que, en el ámbito de la ficción cinematográfica, han dirigido la atención sobre un fenómeno ampliamente normalizado en el continente latinoamericano: el trabajo doméstico, generalmente ejercido por mujeres indígenas de clase trabajadora. La crisis del neoliberalismo en el continente ha provocado el nacimiento de una suerte de estética de lo marginal en la que no sólo los sujetos excluidos por el régimen neoliberal ocupan un lugar central en la narración, sino que el espacio cinematográfico se ve atravesado por figuras periféricas como los niños, las personas LGBTIQ+, los sujetos racializados y, en primera y última instancia, el servicio doméstico. Es por eso que el cine latinoamericano reciente se ha interesado por representar la Otredad desde diferentes perspectivas: la queer — pensemos en filmes como Una mujer fantástica (Sebastian Lelio, 2017) o Las hijas del fuego (Albertina Carri, 2018)—; la cuestión de la raza y la etnia (por ejemplo, Corazón de tiempo, dirigida por Alberto Cortés en 2008); la infancia —en El último verano de la Boyita (Julia Solomonoff, 2009) o La rabia (Albertina Carri, 2008)—; o las subjetividades de clase trabajadora, ejemplificadas en Bolivia (Adrián Caetano, 2001) o La libertad (Lisandro Alonso, 2001).

Explorar la figura de la mucama reviste en ese sentido enorme interés, puesto que se trata de personajes atravesados por vectores identitarios que interseccionan: son mujeres (el Otro de género), generalmente indígenas (el Otro racial) y con un bajo estatus socioeconómico (el Otro de clase). En el sistema neoliberal, el colonialismo ya no se ejerce a través de la violencia o la dominación político-militar, sino a través de relaciones contractuales jerarquizadas. De hecho, la existencia de "mucamas" o "nanas" es una de las formas en las que las clases altas blancas latinoamericanas preservan su posición dominante con respecto a la clase trabajadora, en su mayoría indígena, heredera de esquemas esclavistas y racistas. La cuestión del género resulta también esencial en el posicionamiento de la mucama, que se ocupa de las labores domésticas y de cuidado generalmente asignadas a las mujeres en las sociedades heteropatriarcales.

La representación cinematográfica de la empleada doméstica ofrece además una visión privilegiada del conflicto entre el afecto que fluye entre estas identidades Otras y las familias para las que trabajan, y la distancia que han de mantener a fin de conservar mantener el orden social. Tal y como afirma Margulis (1999: 4), "la otredad es condición normal de la convivencia social y la base de toda identidad colectiva"; a fin de afirmar nuestra identidad, hemos de mantener a otros excluidos, a una cierta distancia, que puede ser más o menos amplia y variar en su carga afectiva. El contexto del hogar ejemplifica en ese sentido las palabras de Oubiña, que afirma que en el cine latinoamericano reciente la política "ha desaparecido como tema porque se ha infiltrado en todos los vínculos" (2008: 39), incluso los afectivos. Se trata entonces de abordar la representación de personajes que, dadas las jerarquías raciales, sociales y sexuales imperantes han estado generalmente invisibilizados en el cine, figuras que, en palabras de Julia Kratje (2017) permanecen "ignoradas, ocultas, sin intereses ni afectos propios: atienden llamadas telefónicas, abren la puerta, transmiten mensajes, cumplen quehaceres extenuantes y desvalorizados por un salario muy bajo y en condiciones laborales con niveles elevados de precariedad y desprotección". 
En este sentido, la proliferación de filmes que dan visibilidad a la mucama latinoamericana se ha visto reflejada en el interés que estas representaciones despiertan desde los Estudios Fílmicos. En 2017, Kratje dedica un artículo a la representación del servicio doméstico en dos filmes latinoamericanos; en el mismo año, Deborah Shaw firma un capítulo sobre la dicotomía intimidad-distancia establecida entre las mucamas y las mujeres de clase media protagonistas de La mujer sin cabeza y El niño pez: Más reseñable todavía será el libro de Elizabeth Osborne y Sofía Ruiz-Alfaro (2020), Domestic Labour in Twenty-First Latin American Cinema, que constituye una de las investigaciones más exhaustivas de las representaciones cinematográficas del servicio doméstico en el cine latinoamericano reciente. El presente artículo se enmarca en esta corriente investigadora, si bien recurrimos a una perspectiva formal (y afectiva) para el análisis no tan presente en los textos aquí citados.

De esta manera, tal y como afirma Mariano Veliz (2017), explorar la proliferación de las voces de esos Otros diversos dentro del cine latinoamericano reciente no sólo supone un fenómeno político, sino que inevitablemente acarrea consecuencias estéticas que se traducen en cambios en el lenguaje audiovisual de estos filmes. En esta última dimensión se enmarca la presente investigación, que aborda la utilización del lenguaje audiovisual háptico (Marks, 2000) para configurar la relación entre la familia burguesa protagonista de La ciénaga y su mucama Isabel (Andrea López); y la implementación de las estrategias del cine lento para representar el carácter monótono y repetitivo de las tareas que lleva a cabo Cleo (Yalitza Aparicio) en Roma. En definitiva, queremos ofrecer dos visiones alternativas a la pregunta de cómo se configura la visibilidad de ese Otro radical que es la sirvienta doméstica indígena, qué lugar ocupa en la narración a nivel afectivo, y cuál es la temporalidad que habita en los filmes seleccionados.

Nos proponemos asimismo explorar el punto de vista desde el que se configuran los filmes, tanto a nivel formal como narrativo y afectivo, puesto que Cuarón y Martel ofrecen propuestas alternativas a la representación de la empleada doméstica a partir de la figura del niño (o niña). En este sentido, nos interesa abordar la cuestión de la Mirada que los directores de los filmes, ambos blancos y pertenecientes a la burguesía despliegan sobre la figura de la empleada doméstica. Si bien la identidad y la subjetividad de ambas mucamas (y, en última instancia, su agencia) son elementos clave en los dos filmes analizados, en ningún momento tratan los cineastas de hablar en lugar de Isabel o Cleo, de "dar voz" a esa Otra subordinada. Gayatri Spivak (1994) habla precisamente de cómo las representaciones artísticas de la mujer subalterna generalmente se llevan a cabo desde una mirada exotizante, condescendiente y que, en última instancia, la condena a la posición del objeto, perspectiva que Martel y Cuarón eluden.

En definitiva, podríamos resumir nuestras hipótesis de trabajo de la siguiente manera: 1) el énfasis en la perspectiva de los niños protagonistas de los filmes sitúa a la mucama en el centro afectivo de las dinámicas familiares; 2) el uso de la imagen-tiempo deleuziana y de las estrategias propias del cine lento visibiliza y subraya el carácter repetitivo y alienante de las labores que llevan a cabo las mucamas; 3) existe una tensión entre intimidad y distanciamiento jerárquico en el trato que las familias blancas de clase media dan a sus empleadas domésticas, manifestada a través de la propia puesta en escena de los filmes. Pensamos, de 
esta manera, que optar por una perspectiva centrada en los afectos y en la dimensión sensual y táctil de la imagen cinematográfica (Marks, 2000) ofrece una alternativa a la Mirada distanciada y fetichizante que tiende a imperar sobre las representaciones cinematográficas de ese Otro de género, raza y clase que es la empleada doméstica indígena. Creemos, asimismo, que los mecanismos de representación del cine lento constituyen una herramienta particularmente adecuada para narrar las vidas de aquellos personajes que ocupan lugares periféricos en el régimen productivo capitalista.

\section{Marco teórico y metodología}

Antes de abordar los instrumentos de análisis que hemos utilizado para abordar la representación de Isabel y Cleo creemos necesario justificar la elección del objeto de estudio. El estatus de Lucrecia Martel como autora de reconocido prestigio en festivales nacionales e internacionales es ya indiscutible; La ciénaga, en concreto, se alzó con el Premio Alfred Bauer en la edición del Festival de Cine de Berlín de 2002, convirtiendo a su directora en una de las cineastas con más prestigio del cine latinoamericano reciente. Por su parte, Roma ganó el Óscar a Mejor Dirección y Mejor Dirección de Fotografía, y Yalitza Aparicio, su actriz protagonista, fue la primera mujer indígena mexicana en ser nominada a Mejor Actriz.

Justificamos asimismo la elección del objeto de estudio desde la óptica comparativa; si bien la mayor parte de filmes latinoamericanos que dan cierto rol protagónico a las empleadas domésticas han sido dirigidos por mujeres - pensemos en cintas como La teta asustada (Claudia Llosa, 2009), El niño pez (Lucía Puenzo, 2009) o La ciénaga - nos parecía interesante comparar la manera en la que Cuarón representa esta figura en oposición a la Mirada femenina (y queer) de Lucrecia Martel. Oponemos, de este modo, la obra de un director que, además de ser hombre, está ligado a los circuitos de cine comercial de Hollywood con el lenguaje cinematográfico utilizado por una directora menos comercial, reconocida además como autora clave en el New Queer Cinema (Rich, 2013). Además, durante los casi veinte años que han transcurrido entre el estreno de La ciénaga y el de Roma no sólo han cambiado las formas de producir y distribuir cine — recordemos que Roma se distribuyó a través de Netflix mientras que La ciénaga ha circulado fundamentalmente a través de festivales - sino que entre medias se han estrenado numerosos filmes que abordan el fenómeno del servicio doméstico en Latinoamérica, la representación de subjetividades indígenas femeninas o las relaciones de poder desiguales en el continente.

En cuanto a la metodología empleada para el análisis de los filmes, ésta se deriva, inevitablemente, de los objetivos e hipótesis de la investigación. Optaremos por el estudio comparativo a partir del análisis del texto, poniendo especial énfasis en aspectos formales y temporales, que tendrán más relevancia que lo relativo a la diégesis: las ideas de Marks (2000) sobre la imagen háptica y las teorizaciones de Deleuze (1987) y Flanagan (2012) sobre la imagen-tiempo y el cine lento serán en este sentido esenciales.

Con respecto a la metodología de análisis háptico de la imagen fílmica, resulta necesario introducir una pequeña definición de este tipo de cine para entender en qué elementos hemos de fijarnos. En el año 2000, Laura Marks introduce en su libro The Skin 
of the Film el concepto de "visualidad háptica", refiriéndose a un tipo de visión — de experiencia espectatorial - que invita a los ojos a operar como el sentido del tacto. Es decir, la Mirada del espectador ya no será distanciada, jerarquizada e incorpórea — como proponía Laura Mulvey (1975) — sino que se tornará en algo capaz de sentir y acariciar (con) los cuerpos y objetos representados en pantalla, ofreciéndose por tanto mecanismos de identificación con los personajes que trascienden lo meramente psicológico (es decir, el nivel de la trama) para llegar a los afectos, la propiocepción y las experiencias encarnadas. La teorización de Marks es heredera de una serie de aproximaciones al cine que se remontan a la fenomenología feminista de Vivian Sobchak (1992), y que parten de una suerte de descontento con la hegemonía de lo visual; tradicionalmente, el dueño de la Mirada (en el cine, pero también en el arte o la fotografía) se conceptualiza como blanco, hombre, heterosexual y de clase media, por lo que se dejarían fuera las vivencias y placeres de toda subjetividad subalterna; entre ellas, la de la empleada doméstica indígena.

Además, según Laura Marks (2000), ciertos filmes presentan imágenes particularmente hápticas, entre los que ella destaca el cine intercultural producido desde la diáspora, por pensar que éste utiliza una imaginería que apela directamente a los sentidos a fin de recuperar esos "recuerdos sensoriales" que se pierden con el trauma del exilio. En este sentido, reivindicamos la importancia de este tipo de análisis para estudiar las representaciones cinematográficas de subjetividades indígenas — particularmente, las femeninas, puesto que el tacto ha tendido a configurarse como un sentido y una forma artística ligada a la feminidad (Irigaray, 1985) — si bien sería interesante aplicarlo a filmes producidos directamente por cineastas mujeres operando en la diáspora.

Por su parte, el cine lento se caracteriza por el uso de tomas largas en oposición al montaje acelerado del cine más comercial; por la presencia de elipsis constantes y estructuras narrativas circulares; por el debilitamiento de las relaciones causa-efecto y la minimización de la trama, que ya no responde a una linealidad teleológica; por los finales abiertos o extremadamente desdramatizados; y por el retrato de los tiempos muertos y la monotonía (Flanagan, 2011). Es interesante destacar que el boom de este tipo de cine en ciertos países — la China de Jia Zhangké, la Hungría de Béla Tarr, o la misma Argentina de Martel— se ha asociado con la irrupción (y, en ocasiones, fracaso) de políticas neoliberales en estos contextos anteriormente "atrasados". Hay en el cine lento un rechazo a la teleología, una reivindicación de la improductividad que lo convierte en medio particularmente apto para el retrato de las vidas de las empleadas domésticas, cuyo trabajo se conceptualiza como de escaso valor dentro del régimen neoliberal.

Aunque la denominación de "cine lento" es relativamente nueva, no lo es tanto la de imagen-tiempo, que Deleuze detectara ya en los años ochenta como propia del neorrealismo italiano, un concepto que nos será de particular utilidad para analizar los tempos pausados y la estética observacional de los filmes objeto de estudio. Para el filósofo francés, en el cine de la imagen-tiempo, la percepción prevalece sobre la acción, y la imagen se subordina al tiempo más allá del movimiento; se produce entonces 
el ascenso de "la situación puramente óptica y sonora que sustituye a las situaciones sensoriomotrices en eclipse" propias del cine de la imagen-movimiento (1987: 13). De esta manera, en el cine lento, los mismos personajes se tornan en una suerte de espectadores; "por más que se mueva, corra y se agite, la situación en que se encuentra desborda por todas partes su capacidad motriz y le hace ver y oír lo que en derecho ya no corresponde a una respuesta o a una acción" (Deleuze, 1987: 13). Se trata de unos personajes que se encuentran impotentes, "apresados en situaciones ópticas y sonoras puras, [...] condenados a la errancia o al vagabundeo" (Deleuze, 1987:63); personajes a menudo infantiles que ven — perciben — en lugar de actuar, puesto que carecen de metas narrativas como tal. Es por eso que, además de prestar atención a las características propias del cine lento, prestaremos particular atención a las instancias en las que los protagonistas de los filmes se convierten en espectadores impotentes de los acontecimientos que les suceden.

\section{Análisis y discusión de los resultados}

\subsection{La construcción del punto de vista en los filmes: la perspectiva del niño y la imaginería háptica}

La perspectiva de los niños queda facilitada de dos maneras diferentes en La ciénaga y Roma: la hapticidad de la primera remite a la forma sensorial y táctil que los niños protagonistas tienen de relacionarse con el mundo mientras que, a nivel formal, en la segunda replica en menor medida esa visualidad desorientadora: los planos de conjunto de la obra de Cuarón (ver por ejemplo fig. 1) permiten al espectador conocer y abarcar los escenarios para orientarse mucho mejor que en el universo laberíntico construido por Martel. Sólo se hace eco visual de la mirada del niño a través de la posición de la cámara, un poco por debajo del nivel de los ojos de un adulto, de manera que, en numerosas ocasiones, las cabezas de los personajes más altos aparecen cortadas. Por el contrario, es la perspectiva del niño que fue Cuarón la que articula el vínculo afectivo con su niñera mixteca, Liboria, encarnada en Cleo; aunque el narrador omnisciente es de alguna manera Cuarón, que recrea sus recuerdos de infancia, la cámara sigue las acciones de Cleo.

Figura 1. Plano de conjunto de la familia cenando y Cleo sirviendo la comida

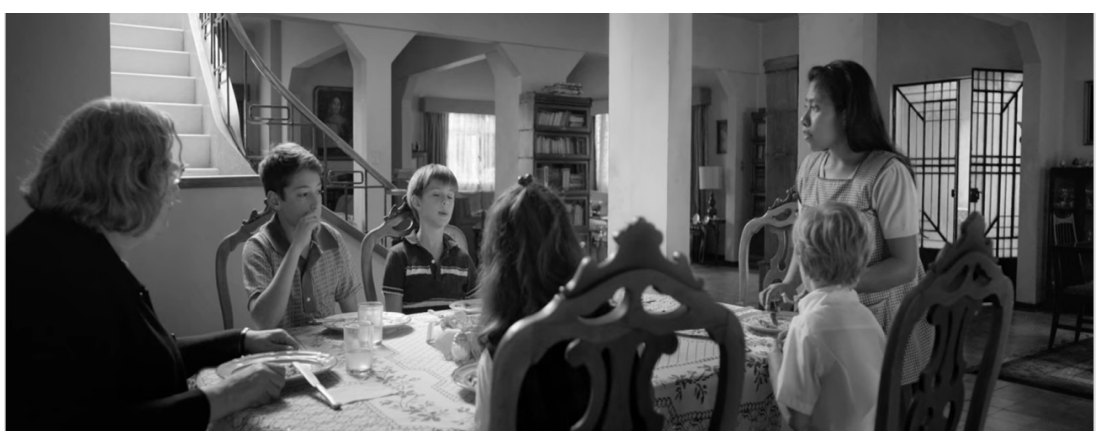

Fuente: fotograma del largometraje Roma (Cuarón, 2018). Netflix, 2018 C) 
Existen contadas excepciones a esta política representacional que permite al espectador la dominación absoluta de la imagen fílmica en Roma: significativamente, sólo se recurre al primer plano o al plano detalle cuando el cuerpo de Cleo trabaja, a fin de enfatizar la materialidad de ese cuerpo que labura, incansable. Por ejemplo, cuando le sirve un huevo pasado por agua a uno de los niños (fig. 2), ejemplo de esas imágenes de gusto que menciona Marks (2000) en sus escritos sobre la hapticidad; cuando friega los platos y la ropa; o cuando realiza sus estiramientos nocturnos junto con Adela, la otra empleada doméstica, enfocándose sus pies. Se opta entonces por un lenguaje audiovisual naturalista, que de alguna manera minimiza la presencia del operador de cámara y ofrece la sensación de realidad vivida y observada, sin ángulos aberrantes ni apenas encuadres que no correspondan a la perspectiva de alguien que contempla la rutina de esa familia desde lejos. La presencia del autor es por tanto menos patente en Roma de lo que lo es en La ciénaga; ni siquiera en las imágenes nocturnas (por ejemplo, Cleo apagando las luces de todas las estancias de la casa mientras la familia duerme) se remite tanto a la materialidad del medio audiovisual como a través de las imágenes a veces desenfocadas, subexpuestas o granuladas que dibuja Martel. Todo es perfectamente nítido, bien iluminado, sin grano.

Figura 2. Primer plano de Cleo sirviendo un huevo pasado por agua

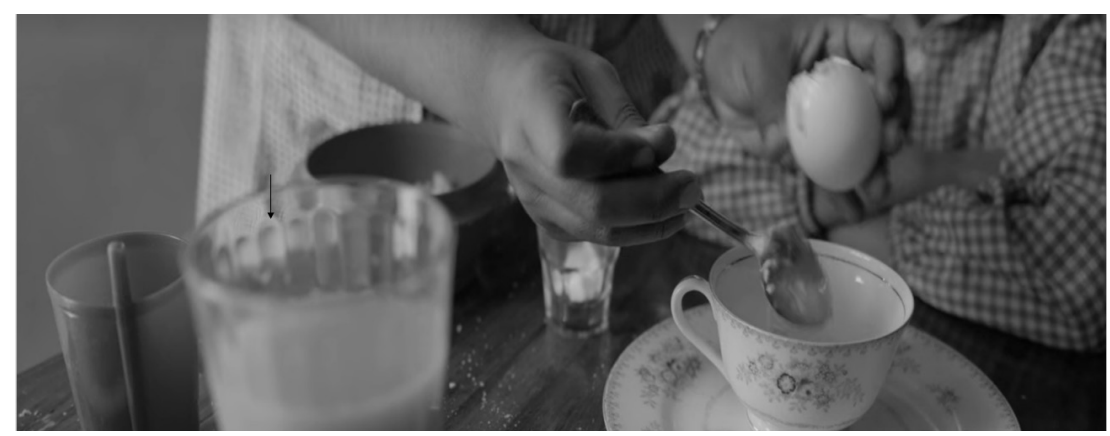

Fuente: fotograma del largometraje Roma (Cuarón, 2018). Netflix, 2018 (C)

Sin embargo, ni la focalización ni la ocularización (Gaudrefault y Jost 1995: 138-139) se producen, en términos generales, desde la posición de la empleada doméstica, cuyas emociones y sentimientos no se nos dan a conocer directamente; por el contrario, dominaría la "ocularización cero, en el uso del nobody's shot que nos acerca a esa experiencia de observadores externos” (Martínez-Cano, 2020: 535). El mismo Cuarón explica en el documental Road to Roma (Andrés Clariond y Gabriel Nuncio) que jamás quiso convertir a Cleo en la narradora de la película, si bien algunos críticos como Richard Brody (2018) afirman que, al representar a Cleo desde la mirada nostálgica del niño que fue, Cuarón reduce a Cleo al estereotipo de ángel silencioso: personaje tolerante, fuerte, y con enorme capacidad para soportar el sufrimiento y el trabajo.

Lucrecia Martel, sin embargo, sí ha sido más vocal sobre la construcción del punto de vista en su cine: para ella, la perspectiva de la cámara equivale de alguna manera a la de los personajes infantiles: "La cámara es un personaje con el que me siento muy identificada. 
Siempre es alguien que pertenece al mundo de lo narrado. Difícilmente, entonces, podría mirar como mira una steadycam, o desde arriba, como lo hace una grúa, o con esa movilidad que puede tener un travelling. Lo que se ve no puede ser algo mirado por nadie; aunque no es ningún personaje en particular, la cámara es alguien" (citada en Oubiña, 2009: 77). Esto explica la proliferación de imágenes parciales, desenfocadas y profundamente desorientadoras en La ciénaga, replicando para el espectador la falta de dominación panóptica de la que los niños, por su menor tamaño, gozan sobre el mundo que los rodea. Se trata de una estrategia visual que ya está presente desde la primera secuencia, que no nos muestra al grupo de adultos que beben al lado de la piscina en plano general, sino que se centra en partes concretas de su cuerpo mientras el primer plano sonoro lo ocupan los hielos que tintinean en las copas que beben, el sonido de las cigarras que cantan en la bochornosa tarde de verano y el ruido que hacen las sillas al arrastrarse (fig. 3).

Figura 3. Primer plano de los adultos de La ciénaga descansando en la piscina

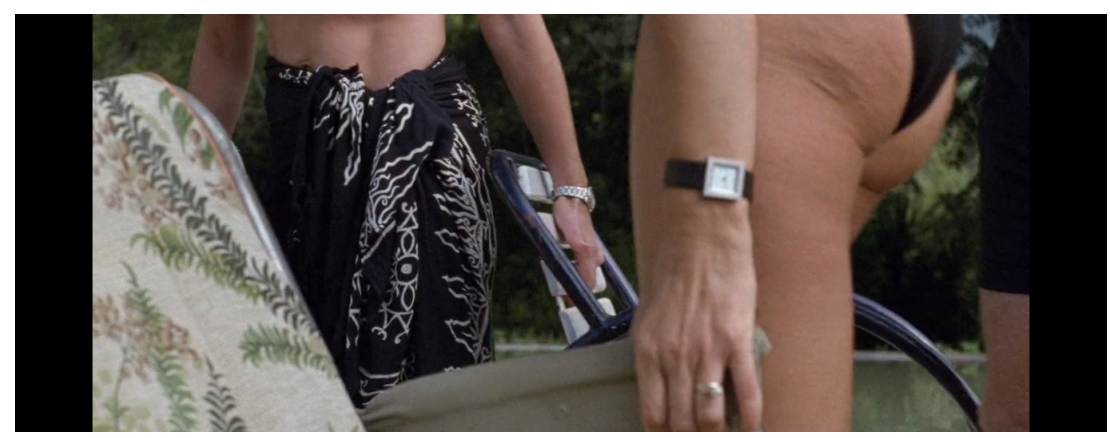

Fuente: fotograma del largometraje La Ciénaga (Martel, 2001). Lita Stantic, 2001 C

Además, el hecho de que, en La ciénaga, la perspectiva de la cámara esté alineada con la de Momi (Sofía Bertolotto) permite construir una perspectiva más encarnada y afectiva sobre el personaje de Isabel, puesto que el hecho de que se contemple su Otredad desde la mirada de una adolescente permite, al menos temporalmente, suspender el juicio moral y el distanciamiento afectivo. Se trata de una elección premeditada: Martel afirma evitar explorar la marginalización desde dentro y opta por la crítica a su propia clase al enfatizar la perspectiva de sus protagonistas infantiles blancos y burgueses, puesto que "esa [la de la mucama indígena] no es su vida" (citada en Rangil, 2005, p. 103). Además, la presencia de niños en el cine, que se relacionan de forma más táctil con el mundo que los rodea — quizás por su impotencia motriz o su curiosidad sensorial - tiende a anclar la experiencia háptica de los filmes (Lury, 2005).

Se ha escrito mucho sobre la presencia de imágenes hápticas en el cine de Martel (ver, por ejemplo, Ríos, 2008), si bien no existe tanta bibliografía que las ponga en relación con la representación de la mucama. En La ciénaga, la sensorialidad de las imágenes que nos muestra la cámara replica la manera extremadamente táctil en la que Momi se relaciona con Isabel, constantemente buscando su contacto. En la secuencia inicial, escuchamos las palabras que, como un rezo, susurra Momi antes de pasar a un primer 
plano de su rostro: "Señor, gracias por darme a Isabel”. En ausencia de un marco narrativo a través del cual interpretar la escena, los espectadores sólo pueden responder al tono establecido por la imagen de los cuerpos tumbados juntos en una habitación oscura en un día soleado, a la sensualidad olfativa de Momi presionando la camiseta de Isabel contra sus fosas nasales (Fig.4) (Molloy, 2017). De este modo, el montaje promueve "correspondencias sensoriales" antes de ofrecer detalles que aclaren las acciones de los personajes, ese deseo prohibido. Una imagen similar se replica cuando su hermana Vero se acerca la camiseta sudada de El Perro, el novio indígena de Isabel, para olerla mientras éste se prueba otra prenda, evidenciándose que el deseo es una de las formas de romper jerarquías raciales y económicas.

Figura 4. Momi aferrándose a Isabel en la cama de su habitación

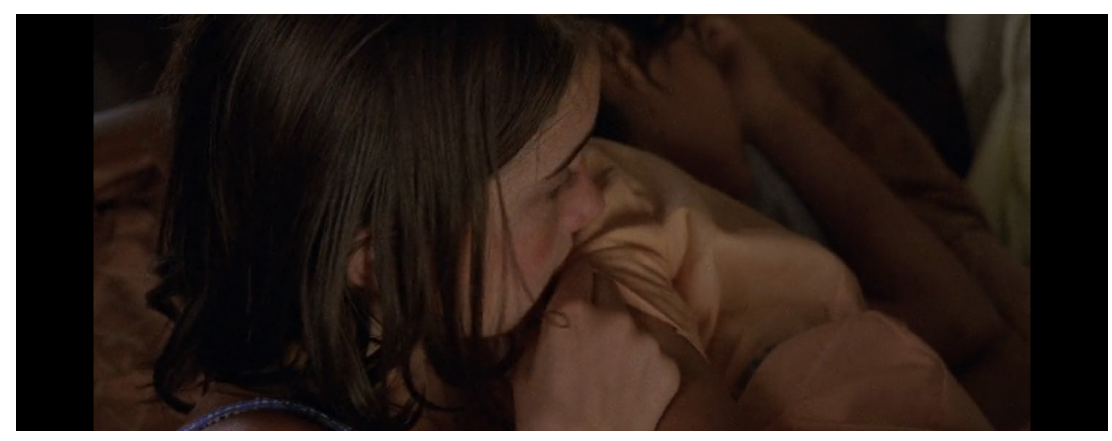

Fuente: fotograma del largometraje La Ciénaga (Martel, 2001). Lita Stantic, 2001 C

Inmediatamente después del momento en la cama con Isabel, Momi va a la habitación de su hermana Vero, y llorando le dice "no quiero estar con nadie más que Isabel", insinuándose su deseo prohibido por la mucama mucho antes de que los espectadores entiendan que transgrede barreras sexuales, de género, raza y clase. Significativamente, Verónica le contesta que su madre (Mecha) tiene pensado despedirla pronto por robar toallas, evidenciándose el contraste entre la forma háptica y afectiva en la que los niños de La ciénaga se relacionan con Isabel y el racismo y clasismo presente en la actitud de los adultos. En este sentido, pensamos que las palabras que Schindel dedica a Roma podrían aplicarse perfectamente a La ciénaga también: "No es que no haya dominantes y dominados, sino que el interés no está puesto tanto en la fractura entre ambos como en el ambiente espeso que unos y otros comparten y en el que sobreviven a su modo" (2019: 4). Ese ambiente es el ambiente de los flujos afectivos, que se establecen entre sujetos tan alejados de la jerarquía como Momi e Isabel, o Paco-Cuarón y Cleo-Liboria.

En cambio, no detectamos un uso tan consistente de imaginería háptica en Roma, quizás debido a que en este filme la cámara no se equipara a un personaje infantil (ni tan siquiera a un personaje). Excepción notoria a esta política es la presencia constante de imágenes de agua, que articulan una experiencia particularmente háptica del cine, 
puesto que, en el agua, las reglas de la gravedad son otras, no sabemos dónde está arriba ni abajo, ni dónde empiezan o terminan los límites de nuestro propio cuerpo (Ahmed, 2006). Significativamente, la mayor parte de imágenes acuáticas del filme se asocian a la presencia de Cleo, pues el patrono de los mixtecos, a cuya etnia pertenece, es Dzahui, el dios de la lluvia. Se trata de planos generalmente más cercanos a los objetos y personas que el resto del filme, imágenes de la empleada doméstica lavando ropa, fregando platos, duchándose (fig. 5) o caminando en la lluvia. En particular, las imágenes de Cleo en la ducha activan los recuerdos sensoriales del espectador al prolongarse en el tiempo y captar el sonido del agua que cae, el vapor que se eleva sobre la piel caliente de la protagonista. Roma comienza además con Cleo fregando los excrementos que el perro de la familia ha dejado en el suelo del garaje. Tanto la imagen del agua que se arrastra lenta e hipnóticamente por las baldosas geométricas como el sonido en off del cepillo que la arrastra hacia el sumidero invocan modos espectatoriales particularmente hápticos, puesto que remiten a nuestros propios recuerdos sensoriales (principalmente táctiles, pero también olfativos y sonoros).

Figura 4. Primer plano de Cleo duchándose en el cuarto de baño

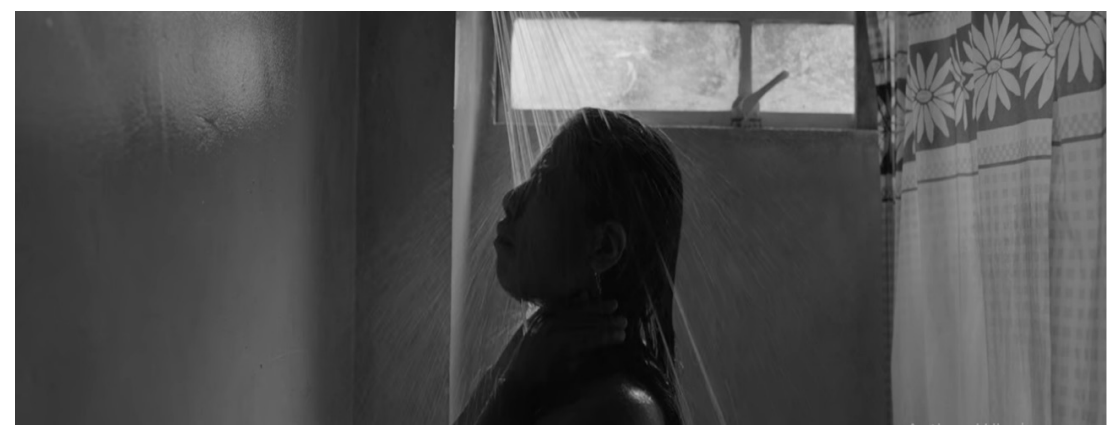

Fuente: fotograma del largometraje Roma (Cuarón, 2018). Netflix, 2018 C)

Sin embargo, el personaje de Cleo sí se relaciona de forma táctil con los niños protagonistas: la vemos acariciarlos constantemente cuando los arropa para dormir, tocándoles el pelo suavemente en el coche al regresar de las vacaciones, o acurrucarse contra ellos en el sofá, invocando la importancia del contacto físico y del afecto como forma de acercamiento al Otro. Otra instancia significativa ocurre cuando Cleo llora porque se ha quedado embarazada, y el Paco le acaricia el vientre mientras canta "sana, sana, culito de rana" y luego la abraza, pero se trata de momentos rodados a una cierta distancia de las pieles que se acarician, y que por tanto no remiten tanto al sentido del tacto del espectador como La ciénaga, no nos sitúan en el cuerpo de Cleo o de los niños. 


\section{2. Un análisis desde el cine lento y la imagen-tiempo}

A mí no me interesa en absoluto contar historias. Pero sí me interesa percibir un proceso. Cuando uno ve una película, no está durante dos horas frente a una historia: está frente a un proceso complejo en donde otro pretende revelarte su percepción del afuera (Martel en Oubiña, 2009: 81).

De acuerdo con Emre Çaglayan (2014, p. 9), cuando se habla de cine lento podemos referirnos a tres aspectos distintos: (1) la estetización de estilo del filme (tomas largas, movimientos de cámara lentos); (2) el tiempo en el que se desarrolla la acción profílmica (movimientos corporales reales de los personajes, staging); y (3) la velocidad a la cual se nos proporciona la información narrativa (forma narrativa, usos de los tiempos muertos) ${ }^{1}$ ". Pasemos a ocuparnos entonces del primero; ya la primera secuencia del filme de Cuarón, en la que vemos a Cleo fregando el patio de la casa, tiene una duración superior a lo que estamos acostumbrados a ver en el cine: ese primer plano dura aproximadamente cuatro minutos y medio, marcando el tempo pausado que será una constante en la película. Asimismo, la escena del parto de Cleo, uno de los clímax dramáticos de la película, tiene una duración de siete minutos en los que la cámara permanece mayoritariamente fija.

Las tomas serán ligeramente menos prolongadas en el filme de Martel, que, como adelantábamos, utiliza el plano de conjunto con menor frecuencia que el director mexicano. Sin embargo, sí nos encontramos con escenas narrativamente inanes de duración muy superior a la media; el inicio del filme, en el que vemos a los adultos de La Mandrágora tomar el sol y emborracharse en torno a la putrefacta piscina, se extiende durante casi tres minutos sin que suceda nada más relevante que la caída de Mecha (Graciela Borges), la matriarca.

Con respecto a los movimientos de cámara, éstos son más numerosos en la obra de Cuarón. Dado que Martel opta por encuadres más cercanos que entreteje a través del montaje a fin de (des)orientar al espectador dentro del plano, no vemos en La ciénaga las lentas panorámicas que utiliza la cámara para seguir a Cleo mientras trabaja en la casa familiar, o los parsimoniosos travellings horizontales que acompañan a los personajes mientras deambulan, como los flaneurs del cine lento, por las calles de Colonia Roma. La misma distancia focal que niega el control panóptico al espectador y subraya la hapticidad de la imagen en La ciénaga imposibilita la utilización de movimientos de cámara como los que implementa Cuarón, si bien el efecto conseguido —esa sensación de durée Bergsoniana, de un tiempo ilimitado y desjerarquizado- es similar.

Por otra parte, el que la cámara permanezca fija en numerosas ocasiones (particularmente en las cenas familiares que se retratan en ambos filmes) posibilita un uso ingenioso del fuera de campo y subraya la dicotomía entre la lejanía y el afecto con el que las familias tratan a

1 In sum, slowness can refer to (1) the film's aesthetization of style (long takes, slow tracking movements), or (2) the time in which the profilmic action unfolds (actual bodily movements of the characters, staging), or (3) the speed in which narrative information is delivered (narrative form, uses of dead time). 
Cleo e Isabel, ese conflicto entre visibilidad y marginalidad. En ese sentido, tanto La ciénaga como Roma hacen uso de lo que Pablo Corro (2012) denominó las "poéticas débiles" del cine latinoamericano, aquellas que, alejadas de la tradición hegemónica de focalizar lo importante en el centro del plano, jerarquizan las acciones a baja intensidad, interesándose por lo que sucede en un segundo plano; es decir, en los movimientos de Cleo o de Isabel, que salen del plano para ir a llevar los platos a la cocina o para llevar a cabo cualquier otra de las faenas interminables que conlleva su rol de mucamas. Así pues, en ambos filmes tiene lugar "el gusto del fuera de campo como margen deliberado para la intervención imaginaria del espectador" (Corro, 2012: 217). Por ejemplo, resulta clave la escena en la que Cleo cena con la familia en el salón, abrazando a uno de los niños mientras todos ven la televisión y ríen mientras ella está, significativamente, sentada en el suelo (fig. 1). La cámara permanece fija mientras ella entra y sale del plano, recogiendo los platos y saliendo del salón para ir a prepararle un té al señor, tal y como le pide Sofía. De esta manera, "por un lado la vemos en los márgenes de la pantalla, siempre dispuesta a desaparecer en pos de una tarea urgente, y por el otro, ocupa a partes iguales el centro del plano, rodeada por los miembros de su familia empleadora" (Vázquez-Rodríguez y Pérez-Nieto, 2020: 544), como sucede en el plano en el que ha rescatado a los niños de morir ahogados, utilizado para la promoción del filme.

La segunda variable supondrá un contraste claro con la duración de las tomas o los movimientos de cámara parsimoniosos de Roma. Ya desde el inicio del filme, el ajetreado movimiento profílmico de Cleo choca con el tempo pausado del filme; atareada con cubo y escoba se mueve a toda velocidad por los diferentes escenarios del hogar familiar, que se encuentra manga por hombro: friega, ordena los cuartos, apaga luces, sube a tender la ropa a la azotea... Durante sus (escasos) períodos de inactividad, sin embargo, "el paso del tiempo es subrayado por el sonido ambiental, en especial cuando suena el reloj" (Sanguinet, 2020: 490), lo que sugiere la idea de un tiempo desperdiciado e inexorable cuando el cuerpo de la empleada doméstica no está inmerso en sus labores. En este sentido, sus repetitivos movimientos contrastan de forma clara con la ociosidad de los niños y los adultos de la familia para que la que trabaja; si bien Sofía se ve obligada a tomar un empleo en una editorial tras el abandono por parte de su marido, no la vemos desempeñar su profesión, y sí tomar el sol en la playa, tumbada en el sofá o esperando que Cleo le sirva la cena en la mesa. En cambio, la mayor parte del tiempo que Cleo ocupa en pantalla se dedica a la repetición de gestos corporales como fregar, lavar la ropa, llevar platos a la cocina o ejercer labores de cuidado con los niños. No en vano se enfatizan en Roma los momentos improductivos, como las vacaciones a la playa o la fiesta de Navidad, que permiten a los adultos que no son sujetos subalternos habitar los mismos tiempos ociosos de la infancia.

La relación entre el tempo aletargado y la corporalidad de los personajes, particularmente la de la mucama, es en este sentido clave; las palabras que Ana Amado dedica a La ciénaga se aplican asimismo a la obra de Cuarón, puesto que se trata de filmes ambos en los que la temporalidad se expresa "a través de las actitudes y posturas del cuerpo, de la repetición ritualizada de las acciones más corrientes, más triviales” (2006: 229). De alguna manera, la repetición de escenas centradas en las tareas manuales que llevan a cabo las nanas subraya el carácter performativo de su género, raza y clase: la reiteración corporal de estos actos y movimientos, subrayada por las estrategias del cine lento, sitúa el cuerpo y el estatus subalterno de 
la mucama en el centro de prácticas discursivas que cuestionan la idea de la identidad como inmutable. Las leemos como mujeres, indígenas y pobres precisamente porque su cuerpo reproduce incansablemente esas tareas domésticas y de cuidado que les han sido asignadas por su posicionamiento en la jerarquía social. El cuerpo de Cleo e Isabel —el cuerpo en general- es el lugar en el que se pone en juego la cultura (Barker, 2000). El cine lento, con su tempo sosegado y su tedioso retrato de los tiempos muertos también solicita una atención por parte del espectador que es de alguna manera trabajo, tal y como explica Schoonover (2012), si bien no se trata de una labor tan física como la que llevan a cabo las mucamas.

Además, en el cuerpo de los personajes y sus actitudes se pueden leer distintas "capas de pasado" (Deleuze, 1987: 229) que remiten a la temporalidad vivida, a la historia de ese sujeto, sus cicatrices y heridas, al igual que el vientre todavía hinchado de Cleo tras el nacimiento de su bebé muerto. En La ciénaga, cuando Mecha se cae en la primera escena se hace numerosos cortes con la copa de vino que ha roto; al acariciar sus cicatrices se lamenta de lo hermoso que era su escote en su juventud, mientras que su marido, antaño un galán, se tiñe y cuida el pelo obsesivamente a fin de conservar su atractivo perdido. Los cuerpos que se nos presentan en La ciénaga son decadentes, aparecen siempre semidesnudos, sudorosos, oprimidos por un clima que los aplasta y que, sobre todo a los adultos, los reduce al rol de zombies impotentes, "semejando prisioneros malditos, desgraciados, abandonados para siempre en una ciénaga infinita” (Felten, 2014: 87).

$\mathrm{Al}$ margen de Isabel, los movimientos corporales de los personajes serán además notablemente más pausados en La ciénaga que en Roma. Ya desde la primera escena vemos a los adultos protagonistas descansando ebrios en las hamacas, como si estuvieran agotados tras un largo día de trabajo; sin embargo, sólo Isabel labura en el filme, puesto que incluso José, el hijo mayor, que trabaja en la empresa familiar en Buenos Aires vuelve a La Mandrágora al inicio del filme para "cuidar" a su madre y se dedica sin embargo a jugar con sus hermanos pequeños y a emborracharse en el carnaval. En esos primeros minutos, los personajes blancos y burgueses arrastran sus sillas y hamacas alrededor de la piscina, moviéndose despacio, como muertos vivientes; en los planos detalle de sus pieles marchitas y celulíticas, la directora nos muestra el paso inexorable del tiempo, el poso de la experiencia vivida. Cuando la matriarca se cae, se limitan a servirse otra copa y decirle a Mecha que se levante, puesto que se acerca una tormenta, que ya se intuye en el plano sonoro; son sus hijas y, sobre todo, Isabel, quienes acuden corriendo a levantarla y a hacerle las curas.

Hay en ese sentido en La ciénaga, una doble velocidad: la de los niños, que interrumpen el letargo de la finca con sus carreras, bailes y explosiones de movimiento y la de los adultos, que asemejan zombies (Amado, 2006). A esa velocidad de los niños habría que añadir, como especifica Dillon (2014) la de Isabel: aunque figura siempre en segundo plano, parece la única que es capaz de actuar frente al solipsismo de los demás, de reaccionar ante su indiferencia; incluso se mueve por la casa a una velocidad diferente a la de los miembros de la familia, al igual que Mamina, la otra mucama. Se trata de una encarnación contemporánea del sísifo indígena cuyas labores no tienen fin: ha de atender llamadas, lavar el "asqueroso" pescado que han capturado los niños con los chicos indígenas en la presa del pueblo o satisfacer las necesidades emocionales de Momi. 
Aquí se evidencia además la impotencia motriz que Deleuze (1987) detectara como propia de los protagonistas del cine lento, epitomizada en el personaje de Mecha que, tras su caída, queda confinada a una cama durante el resto del filme, confirmándose la subordinación de la imagen fílmica al tiempo más allá del movimiento (imposible, en su caso), y construyéndose una narración cinematográfica en la que la percepción prevalece sobre la acción (Acosta y Saisain, 2007: 13). Ella vaga por la escena, siendo testigo de acontecimientos que apenas le conciernen; el embarazo de su mucama (paralelo al de Cleo en Roma), la decadencia económica de la finca La Mandrágora, el affaire que su hijo mantiene con la ex-amante de su marido, etc., sustituyéndose la acción por esas situaciones puramente ópticas y sonoras en las que los medios y los objetos parecen tener más consistencia que las acciones de las personas.

También Cleo encaja con la definición de Deleuze de personaje-espectador; “por más que se mueva, corra y se agite, la situación en que se encuentra desborda por todas partes su capacidad motriz" (1987: 13), como se evidencia en la escena de la Matanza del Corpus. Cleo aparece aquí como muda testigo ante la mirada amenazante de Fermín, que las apunta a ella y a su señora con una pistola. Anteriormente, Cleo se mueve, corre y recorre infructuosamente Ciudad de México para encontrar al padre de su bebé sin lograr ningún avance en su situación, sin progresar la diégesis hacia sus metas narrativas: Fermín rechaza la paternidad del niño sin que ella ofrezca mayor resistencia que unas palabras apenas balbuceadas. Se trata de un personaje pasivo que se deja arrastrar por los acontecimientos y por las decisiones que toman los personajes de su entorno (Fermín, Sofía o incluso los niños); es poco comunicativa, y cuando habla suele hacerlo en idioma mixteco, que sólo comprenden las otras empleadas domésticas, de escasa relevancia narrativa y dramática. En palabras de León Frías, estamos ante una mujer que "casi no se hace notar, como si, una vez más, formara parte constitutiva de ese espacio doméstico" (2021: 120).

Figura 5. Cleo aparece como personaje observador, muda e impotente ante la pistola de Fermín

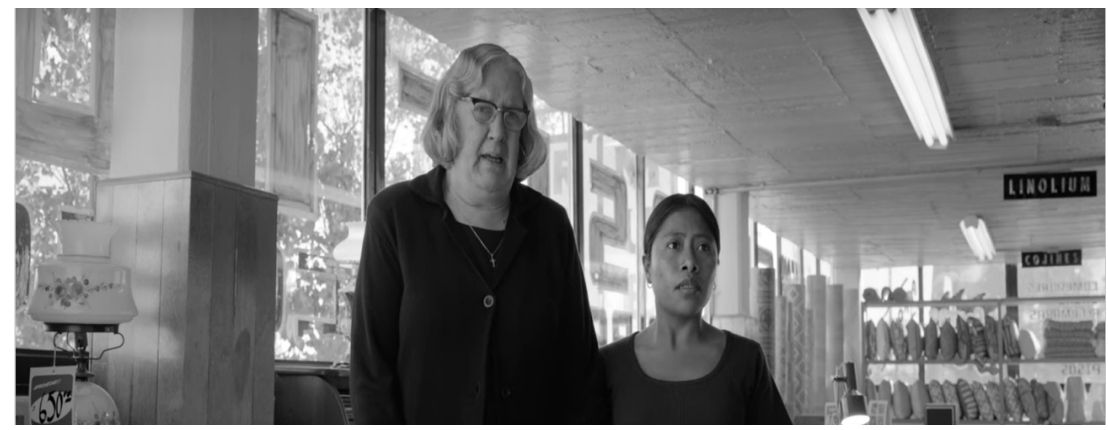

Fuente: fotograma del largometraje Roma (Cuarón, 2018). Netflix, 2018 C)

Por el contrario, Shaw (2018) afirma que, en oposición a la mayoría de los filmes, en los que las empleadas domésticas son figuras casi espectrales, en Roma Cleo es una presencia ubicua 
que se hace notar en casi todos los planos. Sus labores y las dinámicas inconscientes de poder existentes en la familia se hacen visibles a lo largo del filme de forma muy explícita; en La ciénaga esta operación representacional es mucho más sutil, puesto que Isabel aparece colándose entre los marcos del plano, y no sabemos nada de su destino una vez abandona La Mandrágora, no sabemos de ella más que tiene una relación con uno de los chicos del pueblo, El Perro y una hermana que la acoge cuando Mecha la expulsa del hogar familiar debido a su embarazo; ¿qué opina ella de las actitudes racistas y clasistas de los miembros de la familia? ¿cómo se siente con respecto al apego (y velado deseo) que Momi siente hacia ella? Cuando se trata de cine lento, no se intenta ahondar en la psicología de los personajes, de las mucamas, sino que, como si se tratase de un documental de la experiencia vivida por una (dos) familias, se busca mostrar momentos y procesos aparentemente triviales de la manera más opaca y desdramatizada posible. Y es que ni en Roma ni en La ciénaga se activa el envolvimiento emocional del espectador a través de los recursos típicos del melodrama, que, si nos atenemos a la minimalista trama de los filmes, sería el género en el que mejor se encuadrarían estos filmes. Los mecanismos de identificación, tales como la relación plano-contraplano entre los personajes, la jerarquía de sus voces o incluso —en Roma, en concreto- la cercanía de los planos quedan totalmente descartados; tampoco hay música extradiegética que subraye el impacto emocional de ciertas escenas.

Por último, hemos de fijarnos en la velocidad a la cual se nos proporciona la información narrativa: la estructura de la diégesis y el uso de los tiempos muertos. Ambos filmes cuentan con estructuras circulares que reproducen en sus finales lo sucedido al inicio, tanto en el plano simbólico como en el visual. Roma abre con Cleo fregando el suelo el suelo del patio; en el agua jabonosa se refleja la imagen de un avión que atraviesa el cielo. La última escena del filme la muestra tendiendo la colada en la azotea, subiendo las escaleras para realizar las mismas labores que lleva a cabo día tras día; de fondo, otro avión vuelve a atravesar el cielo. Aunque hay un ascenso literal del garaje a la azotea, resulta difícil interpretar en este final una suerte de ascenso social: Cleo ha vivido junto a Sofía el abandono de su marido, ha estado con la abuela en los terroríficos disturbios de la Matanza del Corpus y ha rescatado a los niños de una muerte segura en el mar, fortaleciéndose su vínculo afectivo y su posición como "corazón" de la familia. Sin embargo, sigue ocupando un rol subalterno en la jerarquía, como se evidencia cuando, al regresar de las vacaciones, uno de los niños le pide un licuado de plátano inmediatamente después de relatar que Cleo los ha salvado de morir ahogados. Este final enfatiza de alguna manera la falta de futuro de estos personajes, los Otros de raza, clase y género, negando discursivamente los mitos que el neoliberalismo nos relata.

Por su parte, La ciénaga comienza con la caída de Mecha y termina con la caída, en este caso mortal, de Luchi, su sobrino. El niño se había encaramado a una escalera de mano para contemplar al perro del vecino, pensando que se trataba de la rata africana de la fábula que le contaran sus primas. Más específicamente, los planos finales de Vero y Momi arrastrando las hamacas de la piscina encenagada (fig. 5), que replican la posición de los adultos al inicio del filme (fig. 3) permiten una lectura simbólica todavía más pesimista, que Ana Amado define como "la cancelación de la idea de futuro" (2009: 236). Pudiera parecer que el deseo de Vero por El Perro o el de Momi por Isabel, expresado principalmente a través de la búsqueda del contacto físico; o la contaminación literal y simbólica a la que los niños de la 
familia se exponen en su contacto con el Otro racial (al jugar, por ejemplo, en la presa con los chicos del pueblo, o al mezclarse con ellos en la celebración del Carnaval colla) pondrán fin a las actitudes racistas y clasistas de sus progenitores. Sin embargo, herida por su relación con el Perro al principio, y por su embarazo y huida al final, Momi termina acusando a Isabel de robarle una pulsera; insultándola por su etnia diferente la llama "china carnavalera", haciéndose eco de las palabras de Mecha, que se refiere en todo momento a las personas indígenas como "estos indios" o "estos collas de mierda".

Figura 6. Momi y Vero tumbadas en las hamacas alrededor de la piscina

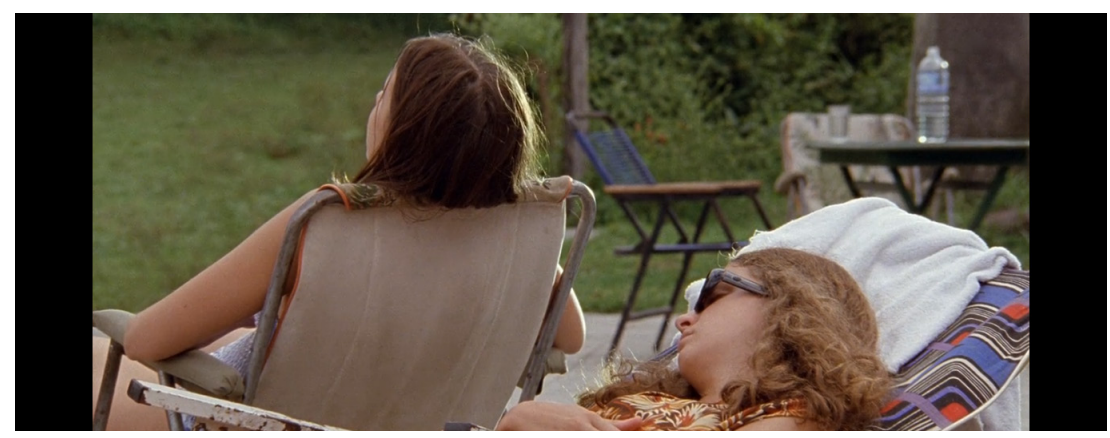

Fuente: fotograma del largometraje La Ciénaga (Martel, 2001). Lita Stantic, 2001 C.

Esa circularidad en la trama va unida a la ruptura de las relaciones causa-efecto y al fin de la teleología narrativa propias del cine lento, y no queda únicamente ejemplificada en el principio y el final de estos filmes. Tras un segundo visionado de Roma o La ciénaga, serán los espectadores quienes, fijándose en los detalles, en pequeños sucesos aparentemente inanes, busquen construir gradualmente una historia coherente que permita dar sentido a los acontecimientos, que no aparecen jerarquizados, sino que semejan meras casualidades. En la obra de Martel, la muerte de Luciano está de alguna manera premonizada por los numerosos acontecimientos violentos que se integran en la trama sin aparente sentido: lo vemos haciéndose el muerto cuando juega con sus hermanas; se interpone entre su primo y la vaca moribunda a la que disparan; se corta al principio de la película, etc. La misma Martel relaciona estas premoniciones con la tradición oral que busca emular: "La muerte de Luciano, que está anunciada un montón de veces, es algo típico de la narración oral: cuando se narra un hecho que ya ha ocurrido, se ven antecedentes de eso que se remontan al nacimiento, como si la persona estuviera condenada desde el comienzo" (citada en Oubiña, 2009: 68).

La muerte del bebé de Cleo también aparece profetizada en varias ocasiones: Paco, al igual que Luchi, se hace el muerto en sus juegos con sus hermanos y su niñera; la primera vez que la mucama acude al hospital para hacerse una ecografía, parte del techo de la maternidad se desprende; y, cuando Cleo está brindando en la fiesta de navidad por la salud de su bebé con los otros empleados domésticos, su vaso se rompe. Se trata de estructuras narrativas que buscan de alguna manera domesticar lo horrible, integrar lo ominoso (ese unbeimlich freudiano) como parte de la cotidianeidad y despojarlo de 
un significado dramático ulterior, rechazando la ilusión de orden y de lógica teleológica que rige el cine de la imagen-movimiento, y que no encaja en las realidades caóticas y violentas que habitan Cleo e Isabel.

Esto se alinea, asimismo, con la desdramatización de los momentos más emocionales de los filmes, rodados con un cierto distanciamiento; la cámara se aleja del rostro de Cleo cuando ella pierde a su bebé (se manifiesta sin embargo su dolor en el plano sonoro, con los sollozos que difuminan el resto de sonidos de la maternidad), y se retrata la salvación de los niños a través de un plano de conjunto que no incluye música diegética ni subraya los diálogos por encima del sonido de las olas del mar. En Roma, tal y como explica López-Agulló, "el acontecimiento no se convierte en acción por medio del acento dramático, sino mediante la mirada de Cleo que abre una interrogación en el centro de la imagen" (2020: 472). En La ciénaga sucede lo mismo: nadie parece llorar la muerte de Luchi, tiene un aire trivial subrayado por las llamadas telefónicas que se intercambian los miembros de la familia. Se concede entonces la misma relevancia dramática, y el mismo tiempo diegético a instancias aparentemente insignificantes como Cleo lavando los platos que a un acontecimiento histórico como la Matanza del Jueves del Corpus, visibilizando y por tanto reivindicando la importancia de las labores que estos sujetos subalternos, generalmente invisibles en las grandes narrativas cinematográficas, llevan a cabo.

\section{Conclusiones}

A través de las estrategias del cine lento y la imagen háptica que ponen el énfasis en los cuerpos de Cleo e Isabel, inmersos en relaciones laborales explotadoras, Roma y La ciénaga invitan al espectador a identificarse emocional y sensorialmente con el personaje de la mucama. Y es que las imágenes hápticas "invitan al espectador a disolver su subjetividad en el contacto cercano y corpóreo con la imagen" (Marks, 2000: 13); de este modo, se fundamenta una relación ética con el cuerpo del Otro: de Cleo, de Isabel, de todas las mucamas. Y, sin embargo, incluso las posibilidades de relaciones transgresoras que se abren a través del deseo y de los espacios táctiles que Momi comparte con Isabel o los niños con Cleo, éstas se ven marcadas por la desigualdad social.

En Roma, el cine-lento se utiliza mucho más para retratar el tedio de las tareas de Cleo, mientras que en La ciénaga esta temporalidad pausada afecta también la vida de la familia burguesa, y es precisamente aquello que posibilita el surgimiento de deseos perversos e intimidades trasgresoras (entre la mucama y Moni) que no están tan presentes en la obra de Cuarón. Para Flanagan, esta "estética de la lentitud" nos obliga a alejarnos de la cultura de la velocidad propia del neoliberalismo globalizado, modificando las expectativas que la audiencia pueda tener sobre la narración fílmica: el destino tanto de Cleo como de Isabel es la inmovilidad social dentro de este régimen, aunque la promesa de la felicidad es mayor para esta última, que huye de La Mandrágora para tener a su bebé en casa de su hermana. Los finales circulares de ambos filmes sugieren que, a pesar de la promesa de salvación que plantea el contacto físico o los vínculos afectivos establecidos con ese Otro racial y de clase - en La ciénaga expresados a través de imaginería háptica en mayor medida que en Roma- 
no hay un futuro en el que las jerarquías sociales vayan a romperse para esas familias. En última instancia, prima la estructura social, las jerarquías raciales y de clase por encima de los vínculos afectivos establecidos con las mucamas protagonistas de estos filmes.

Podalsky (2011) sostiene que la relación entre política y estética es, dentro del cine latinoamericano, más compleja de lo que la crítica ha sugerido, y considera la creación de nuevas "alianzas afectivas" establecidas en películas como las aquí analizadas. Aunque a Roma se le ha acusado de estetizar el duro trabajo de la mucama, y en La ciénaga la crítica social es más bien sutil, se trata de películas que, por su lenguaje audiovisual capaz de generar empatía, "nos tocan", y por tanto tienen tanto o más potencial político que ejemplos procedentes del Nuevo Tercer Cine Latinoamericano (Podalski, 2011: 7). Las consecuencias de este tipo de cine traspasan la gran pantalla para afectar la realidad material de los sujetos que retratan (las mucamas, en este caso); pocos meses después del estreno de Roma, una sentencia del Tribunal Supremo Mexicano garantizó el acceso de los empleados domésticos a la seguridad social y los beneficios sanitarios, decisión que puede haber estado motivada en parte por la mayor visibilización de este fenómeno que trajo consigo el éxito del filme (Osborne y Ruiz-Alfaro, 2020).

\section{Bibliografía}

Ahmed, S. (2006): Queer phenomenology. Durham: Duke University Press.

Amado, A. (2006): Velocidades, generaciones y utopías: a propósito de La ciénaga, de Lucrecia Martel. Alceu, 6(12), 48-56.

Barker, C. (2000): Cultural Studies: Theory and Practice. SAGE.

Brody, R. (18 de diciembre de 2018): There's a voice missing in Alfonso Cuarón's Roma. The New Yorker. Recuperado de: https://www.newyorker.com/culture/the-front-row/theres-avoice-missing-in-alfonso-cuarons-roma.

Corro Penjean, Pablo (2012): Retóricas del cine chileno. Ensayos con el realismo, Santiago: Cuarto propio.

Deleuze, G. (1987) [1985]: La imagen-tiempo. Barcelona: Paidós.

Çaglayan, O. E. (2014): Screening Boredom: the History and Aesthetics of Slow Cinema. Tesis doctoral, Universidad de Kent

Dillon, A. (2014): Figuras de la crisis en el cine de Lucrecia Martel. Questión. Revista especializada en Periodismo y Comunicación, 44(1), 52-66.

Felten, U. (2014): El nuevo cine de mujeres de Latinoamérica: observaciones en torno a la poética transgresiva en La ciénaga de Lucrecia Martel. Área Abierta, 14(3), 80-97. http:// dx.doi.org/10.5209/rev_ARAB.2014.v14.n3.46427. 
Flanagan, M. (2012): 'Slow Cinema': Temporality and Style in Contemporary Art and Experimental Film. Tesis Doctoral, Universidad de Exeter.

Gaudrealt, A. y Jost, F. (1995): El relato cinematográfico. Cine y Narratología. Barcelona: Paidós. Irigaray, Luce (1985): This Sex Which is Not One. Traducido por Catherine Porter. Nueva York: Cornell University Press.

Kratje, J. (2017): Voces y cuerpos del servicio doméstico en el cine latinoamericano contemporáneo. Imagofagia, 15, 1-22.

León Frías, I. (2021): Una aproximación al análisis audiovisual y narrativo de la película Roma. InMediaciones de la Comunicación, 16(1), 113-133. DOI: http://doi.org.10.18861/ ic.2021.16.1.3101.

López-Agulló, J. M. (2020): La forma neorrealista en Roma (Alfonso Cuarón, 2018). En A. Pérez Adroher, M. T. López de la Vieja de la Torre y E. Hernández Martínez (Eds.), Derechos Humanos ante los nuevos desafíos de la globalización. Madrid: Dykinson.

Lury, K. (2005): The Child in Film and Television: Introduction. Screen, 46(3), 307314.

Margulis, M. y Urresti, M. (1999): La segregación negada. Cultura y discriminación social. Buenos Aires: Biblos.

Martinez-Cano, F. (2020): El largometraje Roma como retrato y herramienta prosocial a través de la práctica cinematográfica. En Derechos Humanos ante los nuevos desafíos de la globalización, pp. 520-539.

Marks, L. U. (2002): The Skin of the Film. Durham y Londres: Duke University Press.

Molloy, Missy (2017). Queer-haptic Aesthetics in the Films of Lucrecia Martel and Albertina Carri. Studies in Spanish \& Latin American Cinemas, 14(1), 95-111. doi: 10.1386/ slac.14.1.95_1.

Mulvey, L. (1975): Visual Pleasure and Narrative Cinema. Screen, 16(3), 6-18.

Osborne, E. y Ruiz-Alfaro, S. (2020): Domestic Labor in Twenty-First Century Latin American Cinema. Nueva York: Springer International Publishing.

Oubiña, D. (2008): Construcción sobre los márgenes: itinerarios del nuevo cine independiente en América Latina. En E. Russo (Ed.), Hacer cine. Producción audiovisual en América Latina. Buenos Aires: Paidós.

---. (2009): Estudio crítico sobre "La ciénaga". Buenos Aires: Picnic Editorial.

Podalsky, L. (2011): The Politics of Affect and Emotion in Contemporary Latin American Cinema: Argentina, Brazil, Cuba, and Mexico. Springer.

Rangil, V. (2005): Otro punto de vista. Mujer y cine en Argentina. Rosario: Beatriz Viterbo. 
Rich, R. B. (2013): New Queer Cinema: The Director's Cut. Durham: Duke University Press.

Ríos, H, (2008): La poética de los sentidos en los filmes de Lucrecia Martel. Atenea, 28(2), 9-22.

Sanguinet, L. N. (2020): La identidad a través de la puerta: un topoanálisis de espacios y clases sociales en Roma (Alfonso Cuarón). En Derechos Humanos, pp. 478-498.

Schindel, E. (2019): Martel, Lucrecia (2017). Zama. Película, y Cuarón, Alfonso (2018). Roma. Película. Papeles del CEIC, 64, 1-9.

Schoonover, K. (2012): Wastrels of Time: Slow Cinema's Laboring Body, the Political Spectator, and the Queer. Framework: The Journal of Cinema and Media, 53(1), 65-78.

Shaw, D. (2017): 'Intimacy and Distance'-domestic servants in Latin American women's cinema: La mujer sin cabeza and El niño pez. En Latin American Women Filmmakers: Production, Politics, Poetics (pp. 123-148). Londres: IB Tauris.

---. (24 de diciembre de 2018): Special Dossier on Roma: Children of Women? Alfonso Cuarón's Love Letter to his Nana. Mediático. Recuperado de: https://reframe.sussex. ac.uk/mediatico/2018/12/24/special-dossier-on-roma-alfonso-cuarons-love-letter-to-his-nana/.

Sobchack, V. (1992): The Address of the Eye: A Phenomenology of Film Experience. Princeton: Princeton University Press.

Spivak, G. C. (2002): ¿Puede hablar la subalterna?. Asparkia: investigació feminista, 13, 207-214.

Vázquez-Rodríguez, L. G. y García-Nieto, E. (2020): Manifestaciones del cine lento en la película Roma (2018), de Alfonso Cuarón. Cleo en los márgenes, Cleo en el centro. En Derechos Humanos, pp. 540-558.

Veliz, M. (2017): Figuraciones de la otredad en el cine latinoamericano contemporáneo. Imagofagia, 15. Recuperado de: http://asaeca.org/imagofagia/index.php/imagofagia/article/view/1291 (Consultado el 14/12/2018).

\section{Uso de imágenes}

Las imágenes utilizadas como figuras en este artículo son elementos centrales del análisis, realizado únicamente con fines científicos en el ámbito académico. 
MHJournal Vol. 13 (1) | Año 2022 - Artículo no 5 (198) - Páginas 101 a 122 - mhjournal.org

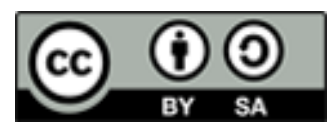

Licencia Creative Commons

Miguel Hernández Communication Journal

mhjournal.org

\section{Cómo citar este texto:}

Lucía-Gloria Vázquez-Rodríguez y Francisco A. Zurian (2021): La representación cinematográfica de la mucama latinoamericana: La ciénaga (Lucrecia Martel, 2001) y Roma (Alfonso Cuarón, 2018), en Miguel Hernández Communication Journal, Vol. 13 (1), pp. 101 a 122. Universidad Miguel Hernández, UMH (Elche-Alicante). DOI: 10.21134/mhjournal. v13i.1469 